\title{
A One-Armed Phase I Dose Escalation Trial Design: Personalized Vaccination with IKK $\beta$-Matured, RNA-Loaded Dendritic Cells for Metastatic Uveal Melanoma
}

\author{
Elias A. T. Koch ${ }^{1,2,3}$, Niels Schaft ${ }^{1,2,3 *}$, Mirko Kummer ${ }^{1,2,3}$, Carola Berking ${ }^{1,2,3}$, \\ Gerold Schuler ${ }^{1,2,3}$, Kenichiro Hasumi ${ }^{4}$, Jan Dörrie ${ }^{1,2,3 \dagger}$ and Beatrice Schuler-Thurner ${ }^{1,2,3 \dagger}$
}

OPEN ACCESS

Edited by: Hubing Shi,

Sichuan University, China

Reviewed by:

Else Marit Inderberg,

Oslo University Hospital, Norway Colt Egelston,

City of Hope National Medical Center, United States

${ }^{*}$ Correspondence: Niels Schaft niels.schaft@uk-erlangen.de

${ }^{t}$ These authors share senior authorship

Specialty section: This article was submitted to Vaccines and Molecular Therapeutics,

a section of the journal

Frontiers in Immunology

Received: 28 September 2021 Accepted: 14 January 2022 Published: 04 February 2022

Citation:

Koch EAT, Schaft N, Kummer M, Berking C, Schuler G,

Hasumi K, Dörrie J and SchulerThurner B (2022) A One-Armed Phase I Dose Escalation Trial Design: Personalized Vaccination with IKK $\beta$ Matured, RNA-Loaded Dendritic Cells for Metastatic Uveal Melanoma.

Front. Immunol. 13:785231.

doi: 10.3389/fimmu.2022.785231
${ }^{1}$ Department of Dermatology, Universitätsklinikum Erlangen, Friedrich-Alexander-University Erlangen-Nürnberg (FAU), Erlangen, Germany, ${ }^{2}$ Comprehensive Cancer Center Erlangen-European Metropolitan Region of Nuremberg (CCC ER-EMN), Erlangen, Germany, ${ }^{3}$ Deutsches Zentrum Immuntherapie (DZI), Erlangen, Germany, ${ }^{4}$ ICVS Tokyo Clinic, Chiyoda-ku, Japan

Uveal melanoma (UM) is an orphan disease with a mortality of $80 \%$ within one year upon the development of metastatic disease. UM does hardly respond to chemotherapy and kinase inhibitors and is largely resistant to checkpoint inhibition. Hence, further therapy approaches are urgently needed. To improve clinical outcome, we designed a trial employing the $3^{\text {rd }}$ generation personalized IKK $\beta$-matured RNA-transfected dendritic cell (DC) vaccine which primes T cells and in addition activates NK cells. This ongoing phase I trial [NCT04335890 (www.clinicaltrials.gov), Eudract: 2018-004390-28 (www. clinicaltrialsregister.eu)] investigates patients with treatment-naive metastatic UM. Monocytes are isolated by leukapheresis, differentiated to immature DCs, matured with a cytokine cocktail, and activated via the NF- $\mathrm{KB}$ pathway by electroporation with RNA encoding a constitutively active mutant of IKKK . Three types of antigen-RNA are coelectroporated: i) amplified mRNA of the tumor representing the whole transcriptome, ii) RNA encoding driver mutations identified by exome sequencing, and iii) overexpressed non-mutated tumor antigens detected by transcriptome sequencing. This highly personalized DC vaccine is applied by 9 intravenous infusions in a staggered schedule over one year. Parallel to the vaccination, standard therapy, usually an immune checkpoint blockade (ICB) as mono (anti-PD-1) or combined (anti-CTLA4 and anti-PD-1) regimen is initiated. The coordinated vaccine-induced immune response encompassing tumorspecific T cells and innate NK cells should synergize with ICB, perhaps resulting in measurable clinical responses in this resistant tumor entity. Primary outcome measures of this trial are safety, tolerability and toxicity; secondary outcome measures comprise overall survival and induction of antigen-specific T cells.

Keywords: metastatic uveal melanoma, tumor antigen vaccine, personalized vaccine, Immune checkpoint blockade, tumor antigens, IKK $\beta$-matured dendritic cells 


\section{INTRODUCTION}

Uveal melanoma (UM) is the most common tumor of the eye in adults but still represents a rare subtype of melanoma. The mean age-adjusted incidence is 5.1 per million in the United States, and shows a north to south gradient in Europe from a minimum of 1.5 per million in southern Italy up to 9.2 per million in Ireland (1-3). The primary tumor of UM can be treated successfully regarding clearance and low intraocular recurrence rates. The treatment approach depends on the tumor size, patient preference, and tumor localization, most commonly including brachytherapy or enucleation $(4,5)$. Nevertheless, at least 40 $50 \%$ of patients will develop metastases depending on genetic aberrations of the tumor, which spread predominantly to the liver $(6,7)$. Since there is no effective standard treatment for advanced UM, the prognosis is bleak once metastasis develops (8). A meta-analysis of a population including 912 patients from clinical trials showed a median overall survival (OS) of 10.2 months, whereby $15 \%$ received checkpoint blockade (ICB) and $34 \%$ chemotherapy (9). Recently published phase II trials of patients treated with combined ICB showed a more favorable OS of 19.1 and 12.7 months $(10,11)$. These data are in line with results in a real-world setting and are better than the proposed values before the ICB era (12-15). However, the therapeutic benefit of ICB is small, and at the cost of severe immune-related adverse events (AE) potentially involving all organ systems by a broad activation of the immune system. These AE can be challenging to manage, often require treatment interruption, systemic immunosuppression, and, in case of intolerable toxicity, a treatment discontinuation (16-18). Grade 3-4 drugrelated $\mathrm{AE}$ occur in up to $57 \%$ of patients treated with nivolumab plus ipilimumab $(10,11,14)$. Tebentafusp (IMCgp100), a firstin-class soluble T-cell engager (so-called ImmTACs), achieved for the first time prolongation of OS in a randomized trial in metastatic uveal melanoma, and is currently awaiting approval in the United States. The drug consists of a soluble TCR, binding to gp100 peptide/HLA-A ${ }^{*} 02: 01$ complexes, which is fused to an anti-CD3 scFv. Following signs of clinical efficacy in early clinical trials (NCT02570308) (19), a recent phase III trial demonstrated a clinically meaningful, significant improvement of OS as firstline treatment (median OS 21.7 versus 16.0 months for patients randomized to investigator's choice, i.e., pembrolizumab, ipilimumab or dacarbazine; $\mathrm{P}<0.0001$; stratified HR 0.51 [95\% CI 0.37-0.71]) (20). Progression-free survival was also improved compared to ICB (3.3 versus 2.9 months, $\mathrm{P}=0.0139$; HR 0.73 ). Interestingly, the ORR remained low (9\% with IMCgp 100 versus $5 \%$ with ICB) yet prolonged survival could be observed even in patients who progressed. This novel therapy seems relatively safe with cutaneous (rash, pruritus) and cytokine-mediated side effects (pyrexia, cytokine-release syndrome) but no treatmentrelated death and a low discontinuation rate (2\% versus $4.5 \%$ with IC). Despite this advance, the prognosis for metastatic uveal melanoma stays dismal, notably for $\mathrm{HLA}-\mathrm{A}^{\star} 02: 01$ negative patients who do not qualify for IMCgp100 therapy. Thus, further therapeutic approaches for advanced UM are urgently needed. Building on our expertise with RNA-transfected $2^{\text {nd }}$ generation dendritic cell (DC) vaccines (NCT00074230, NCT01983748), and promising observations in compassionate treatments of UM (21), we designed a trial employing the $3^{\text {rd }}$ generation personalized IKK $\beta$-activated RNA-transfected DC vaccine (22). By activation of NF- $\mathrm{KB}$ via the introduction of a constitutively active stabilized mutant of IKK $\beta$, these DCs express increased levels of co-stimulatory molecules, induce better memory CTL responses, and are in addition effective activators of NK cells $(23,24)$. The DCs are loaded with amplified tumor mRNA and an individualized selection of shared UM-associated antigens and driver mutations based on exome and transcriptome sequencing of a tumor biopsy.

\section{METHODS AND ANALYSIS}

We are currently performing the phase I trial (NCT04335890) in patients with recently diagnosed metastatic UM, which is not curable with local therapy. We intend to treat and fully evaluate 12 patients aged between 18 and 75 years and irrespective of race and gender with a WHO performance status of 0,1 , or 2 . Patients must have accessible metastases, which can be biopsied or surgically removed to obtain material for total tumor mRNA production and next generation sequencing (NGS). After tumor sampling, we extract RNA and DNA. mRNA is subjected to whole transcriptome sequencing and DNA to whole exome sequencing. With the help of the exome data, we select highly expressed antigens from a predesigned warehouse of UM antigen-encoding mRNAs: Tyrosinase, gp100, PRAME, MAGEA3, and IDO1. For IDO1 a functionally inactive mutant was designed to circumvent its immunosuppressive activity. The exome data are also used to determine which common driver mutations are present in each individual tumor. The corresponding $\mathrm{mRNAs}$ are taken from a predesigned warehouse: $\mathrm{GNAQ}_{\mathrm{R} 183 \mathrm{Q}}, \mathrm{GNAQ}_{\mathrm{Q} 209 \mathrm{~L} / \mathrm{P}}, \mathrm{GNA} 11_{\mathrm{Q} 209 \mathrm{~L} / \mathrm{P}}, \mathrm{SF} 3 \mathrm{~B} 1_{\mathrm{R} 625 \mathrm{H} / \mathrm{C}}$, CYSLTR2 $2_{\mathrm{L} 129 \mathrm{Q}}$, and PLCB4 $4_{\mathrm{N} 630 \mathrm{Y}}$. The use of a prefabricated warehouse of common antigens and driver mutations allows the production of a highly individualized vaccine in a very short time. To facilitate both MHC class I and II-restricted presentation, the antigens are equipped with the leader peptide from Lamp-1 (amino acid 1-27; GenBank: AAL58070.1) and the 40 C-terminal aminoacids from Lamp-3 (DC-LAMP; GenBank: AAH32940.1) which direct them to both presentation pathways (25).

To obtain the required numbers of autologous DCs, a monocyte concentrate is collected via leukapheresis. Monocytes are purified by counterflow-elutriation and subsequently differentiated to immature DCs over 6 days in RPMI1640 supplemented with $1 \%$ autologous plasma, 1glutamine, GM-CSF, and IL-4. Then cells are exposed to a standard maturation cytokine cocktail (TNF $\alpha$, IL-1 $\beta$, IL-6, and $\mathrm{PGE}_{2}$ ) (26) for $24 \mathrm{~h}$. After the DCs are matured, they are divided into three equal parts. One batch is electroporated with the respective common uveal melanoma tumor-associated antigens (gp100, tyrosinase, PRAME, MAGE-A3, IDO1), one batch with RNAs coding for common driver mutations known to occur in uveal melanoma (GNAQ, GNA11, SF3B1, CYSLTR2, PCLB4) 
and one batch with autologous tumor RNA (Table 1). No more than 3 antigens will be used in one batch. In addition, all DCs are electroporated with mRNA coding for a constitutively active, stabilized variant of IKK $\beta$ to activate the NF- $\kappa B$ pathway. Electroporation conditions are: square wave pulse, $1250 \mathrm{~V} / \mathrm{cm}$, pulse time $1 \mathrm{~ms}$, described in detail elsewhere (27). These superactivated DCs (NF- $\mathrm{KB}-\mathrm{DCs}$ ) produce inflammatory cytokines, induce better memory CTL responses, and also activate NK cells (Figure 1) (24).

Four hours after the electroporation process, the DC are mixed, cryopreserved and stored in cryo vials (consisting of $15 \times 10^{6}$ cells, autologous serum, 10\% DMSO, and 5\% glucose) in the gas phase of liquid nitrogen $\left(<-150^{\circ} \mathrm{C}\right)$ under appropriate, continuous monitoring of temperature. The NF- $\kappa \mathrm{B}-\mathrm{DCs}$ are tested for sterility and can only be administered to the patient afterwards. We expect 50 to $80 \%$ of the DCs to survive the procedure of both electroporation and cryoconservation, as we described earlier (28). At the visits, the DCs are thawed, resuspended in $50 \mathrm{ml} 0,9 \% \mathrm{NaCl}$ and administered intravenously to the patient within half an hour. The vaccine is applied with an intra-patient dose escalation of 7.5 to 30 million cells separated into three cohorts with increasing starting dose (Table 2). The vaccines are scheduled for 9 visits in increasing intervals of 2, 4, and 6 weeks over one year. In parallel to the vaccination, the patients receive the standard treatment for metastatic UM guided by a multi-disciplinary tumor board decision, preferably ICB as either mono- (PD-1 antibodies) or combined (PD-1 and CTLA-4 antibodies) treatment. The two therapies are administered independently in their appropriate interval with a minimum distance of 2 days to each other. Every three months, a tumor staging including MRI- and CT-scans is performed (Figure 2).
Primary outcome measures within a period of one year are safety, dose-limiting toxicities, and maximum tolerated dose assessed by side effects using the Common Toxicity Criteria (CTC v4.0), as well as tolerability assessed by quality of life questionnaire (EORTC QLQ-C30, Version 2). Secondary predefined outcome measures are the 2-year OS and the induction of antigen-specific $\mathrm{CD}^{+} \mathrm{T}$ cells and/or $\mathrm{CD}^{+} \mathrm{T}$ cells against tumor-associated antigens and mutated drivers.

Due to the explorative nature of this phase I trial, all analyses will be descriptive and no confirmatory statistical testing is intended. The sample size of 12 evaluable patients was chosen as this number is sufficient to detect effects that increase in frequency from $5 \%$ in the population to $30 \%$ in the treated individuals with a power of over $80 \%$ and false positive probability of under $5 \%$. The same applies to effects with a $10 \%$ frequency in the population and a $40 \%$ frequency in the treated patients.

\section{DISCUSSION}

Vaccination with peptide-loaded, monocyte-derived and cytokine-matured DCs ( $1^{\text {st }}$ generation DCs) induced tumorspecific class I and class II responses linked to an increased median overall survival (29). Such DCs, yet loaded with antigencoding mRNAs rather than peptides ( $2^{\text {nd }}$ generation DCs), in a subsequent phase I/II trial (NCT00074230) in 82 metastasized cutaneous melanoma patients, also induced the highest vaccinespecific immune responses in long-term survivors ( $>6$ years), again without significant side effects (30).

The use of the highly potent, IKK $\beta$-activated, RNA-loaded designer DCs ( ${ }^{\text {rd }}$ generation DCs) as adjuvant, combined with

TABLE 1 | Description of the antigen platform.

\begin{tabular}{|c|c|c|}
\hline & Targets & Description \\
\hline \multirow{5}{*}{$\begin{array}{l}\text { Tumor- } \\
\text { associated } \\
\text { antigens }\end{array}$} & $\begin{array}{l}\text { Glycoprotein } 100 \\
\text { (gp-100) }\end{array}$ & Transmembrane glycoprotein, highly expressed in normal melanocytes and melanoma cells. \\
\hline & PRAME & PRAME is an antigen that is predominantly expressed in melanomas with a low expression in non-tumor tissue. \\
\hline & $\begin{array}{l}\text { Indoleamine-pyrrole } \\
\text { 2,3-dioxygenase } \\
\text { (IDO) }\end{array}$ & $\begin{array}{l}\text { An enzyme expressed by tumor cells in response to inflammation and limits T-cell function. Plays a potential role in the immune } \\
\text { escape mechanism. }\end{array}$ \\
\hline & $\begin{array}{l}\text { Melanoma- } \\
\text { associated antigen } 3 \\
\text { (MAGE-A3) }\end{array}$ & $\begin{array}{l}\text { MAGE-A3 is a tumor-specific protein. It has been identified on several tumor entities including uveal melanoma. The function is } \\
\text { unknown. }\end{array}$ \\
\hline & Tyrosinase & A copper-containing enzyme in the melanosomes, which plays an important role in the melanogenesis. \\
\hline \multirow{5}{*}{$\begin{array}{l}\text { Driver } \\
\text { mutations }\end{array}$} & GNAQ & Driver mutation leads to activation of G protein-coupled receptor (GPCR) and to the carcinogenesis with no correlation to OS. \\
\hline & GNA11 & Driver mutation leads to activation of G protein-coupled receptor (GPCR) and to the carcinogenesis with no correlation to OS. \\
\hline & SF3B1 & Hot-spot mutation correlating with a peak of metastases after 7 years (intermediate risk of metastases). \\
\hline & $\begin{array}{l}\text { Cysteinyl leukotriene } \\
\text { receptor } 2 \\
\text { (CYSLTR2) }\end{array}$ & $\begin{array}{l}\text { CYCLTR2 mutation activates G } \alpha \text { q in tumors lacking GNAQ, GNA11, and PLCB4 mutations promoting tumorigenesis without } \\
\text { initiating metastasis. }\end{array}$ \\
\hline & $\begin{array}{l}\text { Phospholipase C } \beta 4 \\
\text { (PCLB4) }\end{array}$ & $\begin{array}{l}\text { Mutation in the PCLB4 activates signaling downstream of GPCR by directly binding Gaq promoting tumorigenesis without initiating } \\
\text { metastasis. }\end{array}$ \\
\hline \multicolumn{2}{|c|}{ Autologous tumor RNA } & $\begin{array}{l}\text { Autologous RNA is extracted from a patient's tumor sample obtained at biopsy or surgery. Total tumor RNA is extracted from the } \\
\text { tumor cells, and tumor RNA is amplified using PCR amplification of a complementary DNA (CDNA) intermediate followed by in vitro } \\
\text { transcription. }\end{array}$ \\
\hline
\end{tabular}

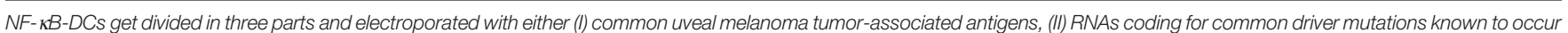
in uveal melanoma, or (III) autologous tumor RNA. 


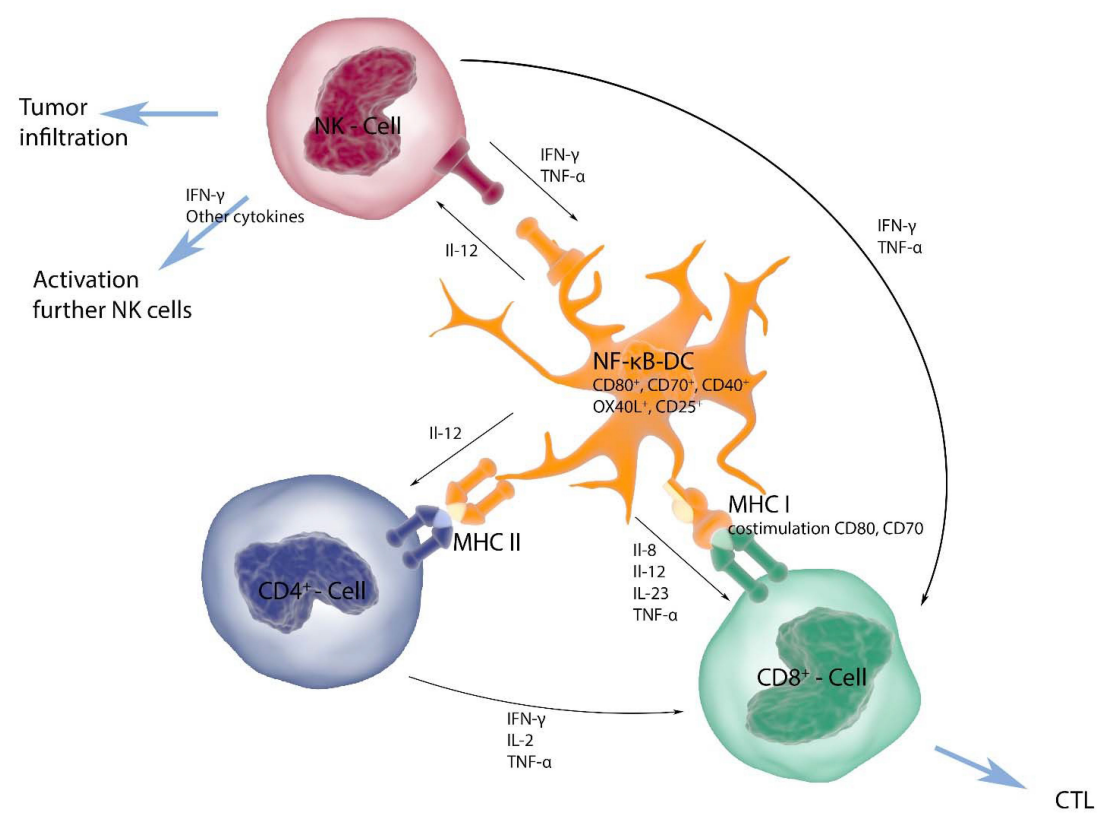

FIGURE 1 | DCs present tumor antigens through MHC class I and II to CD8 ${ }^{+}$and CD4 ${ }^{+} \mathrm{T}_{\text {cells, }}$ respectively, and are able to activate innate immune cells, like NK cells. T-cell priming is supported by co-stimulatory molecules and the secretion of pro-inflammatory cytokines. NF- $\mathrm{BB}$-activated DCs express increased levels of the classical co-stimulatory molecules CD80 and CD86, but also of CD70, CD40, OX40L, and several pro-inflammatory cytokines, such as IL-12 and TNF $\alpha$, which support induction of memory T-cell responses and increase NK-cell activation and proliferation. The antigens used in this trial are modified in such a way, that both MHC class I- and class II-restricted presentation is facilitated. Therefore, a comprehensive cellular response of helper T cells, cytotoxic T cells, and NK cells is induced, which in turn produce additional cytokines that support activation.

an individual selection of tumor neo-antigens and overexpressed antigens in this first-in-human trial holds great promise. Based on preclinical data and the study design we expect that i) more and better tumor-specific helper as well as cytotoxic $\mathrm{T}$ cells are induced in the UM patients, ii) NK cells get also activated resulting in a coordinated adaptive and innate immune response, and iii) that these immune responses are supported by ICB. Therefore, we expect that a prolonged survival may be achieved compared to ICB alone. However, this chance comes with potential risks of toxicity for the treated individuals, but experience with another type of highly activated DCs suggests that these should be manageable (31).

Although expressing tumor drivers in cellular drug products may raise the concern of malignant transformation of these cells, our antigen constructs are highly unlikely to induce cancer, because they only consist of small parts of the functional proteins. In addition, the cell type we are using is terminally differentiated and no malignancies arising from these cells have been described so far. Most importantly, the introduced proteins are expressed in a transient fashion by mRNA electroporation, which makes a functional integration into the genome of any cell impossible.

Concerning the induction of autoimmunity induced against the somatically mutated driver epitopes, we consider this risk lower than for non-mutated tumor antigens that have been used for decades without inducing dangerous autoimmunity. The beauty of this new class of tumor epitopes is their specificity exclusively for the tumor because they are only mutated in the malignant tissue, while all non-malignant tissues do not harbor the mutation. Hence, we think these antigens are both more efficient against the tumor, and less prone of inducing any autoimmune response. Further, the use of highly expressed antigens from a predesigned warehouse of UM antigenencoding mRNAs seems promising, as these antigens have been used in previous vaccination trials without causing severe autoimmunity. All antigens except for IDO were even used in

TABLE 2 | Vaccination schedule with 9 visits.

\begin{tabular}{|c|c|c|c|c|c|c|c|c|c|}
\hline Patient number & Vacc \#1 & Vacc \#2 & Vacc \#3 & Vacc \#4 & Vacc \#5 & Vacc \#6 & Vacc \#7 & Vacc \#8 & Vacc \#9 \\
\hline $1-4$ & $7.5 \times 10^{6}$ & $7.5 \times 10^{6}$ & $15 \times 10^{6}$ & $15 \times 10^{6}$ & $30 \times 10^{6}$ & $30 \times 10^{6}$ & $30 \times 106$ & $30 \times 10^{6}$ & $30 \times 10^{6}$ \\
\hline $5-8$ & $15 \times 10^{6}$ & $15 \times 10^{6}$ & $30 \times 10^{6}$ & $30 \times 10^{6}$ & $30 \times 10^{6}$ & $30 \times 10^{6}$ & $30 \times 10^{6}$ & $30 \times 10^{6}$ & $30 \times 10^{6}$ \\
\hline $8-12$ & $30 \times 10^{6}$ & $30 \times 10^{6}$ & $30 \times 10^{6}$ & $30 \times 10^{6}$ & $30 \times 10^{6}$ & $30 \times 10^{6}$ & $30 \times 10^{6}$ & $30 \times 10^{6}$ & $30 \times 10^{6}$ \\
\hline
\end{tabular}

Patients will be vaccinated in a staggered approach by selectively decelerating release of the vaccine in increasing intervals of 2, 4, and 6 weeks. 


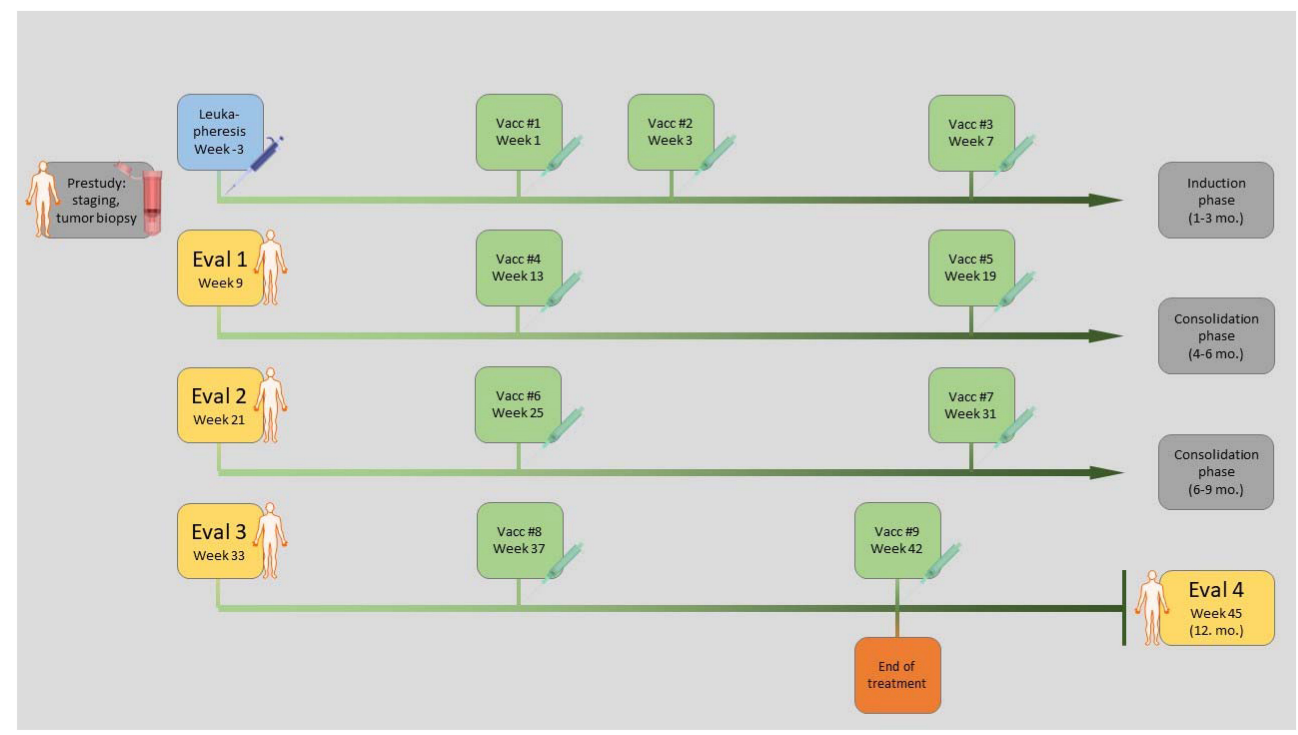

FIGURE 2 | Treatment schedule: Initially a tumor biopsy is taken, and RNA and DNA preparation and sequencing is performed. To obtain the required numbers of autologous DCs, a monocyte concentrate is collected via leukapheresis. The vaccine is generated by RNA-electroporation of DCs and 9 vaccine injections are given intravenously over a period of one year. Every three months CT/MRI staging is performed.

trials with mRNA-electroporated DCs [reviewed in (32)]. IDO plays potentially a role in the immune escape mechanism of UM as it is upregulated as response to IFN- $\gamma$ and it might be necessary as a therapy target for a sustainable immune response (33). However, IDO is ubiquitously expressed but also plays a role in immune-protection of human corneal cells and could lead to autoimmunity (34) Nevertheless, it was shown to be a safe target in a peptide vaccination trial (35). Despite combination with ipilimumab and detection of IDO-specific T cells, no autoimmunity was observed (35). MAGE-A3 and PRAME are rarely expressed in somatic tissue and harbor a low risk for autoimmunity. The antigens gp100 and tyrosinase are also expressed by melanocytes and can lead to cutaneous adverse events as one could see in the IMCgp100 trial with the occurrence of $83 \%$ rash, $69 \%$ pruritus, $25 \%$ erythema, $21 \%$ skin exfoliation, $20 \%$ hair color changes, and $16 \%$ vitiligo (36). Nevertheless, both are well established melanoma antigens for immunotherapy, which have been used in various clinical trials with DCs (32).

The special feature of the NF- $\mathrm{KB}-\mathrm{DCs}$ we test in this trial is their ability to produce cytokines, most importantly biologically active IL-12. This facilitates the formation of a cellular immunological memory, but since cytokine release syndrome is a major risk in other cellular immunotherapies, this topic needs to be addressed: The maximum tolerated dose for IL-12 is above $100 \mathrm{ng} / \mathrm{kg}$ and the lowest dose observed to cause mild side effects is $3 \mathrm{ng} / \mathrm{kg}(37,38)$. Our maximum vaccination dose of 30 million DCs would result in a dose of only $0.6 \mathrm{ng} / \mathrm{kg}$ in patients with $75 \mathrm{~kg}$ body weight, because one million of DCs produce around $1.66 \mathrm{ng}$ (39). For other cytokines, produced by the NF$\kappa \mathrm{B}$-activated DCs the relations of doses are similar. Hence, we think that the produced cytokines will be effective in the microenvironment during $\mathrm{DC} / \mathrm{T}$-cell interaction to induce a favorable T-cell phenotype, but will not have toxic systemic effects.

Measuring the $\mathrm{T}$-cell responses induced by the vaccine will be challenging, since the use of full-length antigens results in all possible HLA-restricted peptides. To tackle this, we have established an EliSpot-based method, which uses again mRNAelectroporation for antigen-loading (40). This method is HLAhaplotype independent, and will give initial information, which patients responded to which antigen. Those will then be analyzed in more detail, using epitope prediction algorithms like netMHC (41) and multicolor-combicoded HLA-peptide-multimers (42). Alternatively, $\mathrm{T}$ cells can be stimulated by mRNA-transfected targets and then be subjected to a MANAFEST-assay (43), to determine specific reactivity. The immunological responses may then be correlated with the clinical outcome.

\section{CONCLUSIONS}

We anticipate that our $3^{\text {rd }}$ generation DC vaccine induces highquality tumor-specific helper and cytotoxic $\mathrm{T}$ cells and activates NK cells. The use of a prefabricated warehouse of antigens to select from based on individual NGS-data of the tumor allows the rapid production of a highly individualized cellular vaccine. The specific and coordinated immune response should synergize with the block of inhibitory checkpoints, perhaps resulting in measurable clinical responses in this resistant tumor entity.

The first results from this trial are expected in 2022. 


\section{DATA AVAILABILITY STATEMENT}

The original contributions presented in the study are included in the article. Further inquiries can be directed to the corresponding author.

\section{ETHICS STATEMENT}

The studies involving human subjects were reviewed and approved by Ethikkommission of the Friedrich-Alexander University Erlangen-Nürnberg. The patients provided their written informed consent to participate in this study. The principal investigator and all other investigators ensure that this study will be conducted in full conformity with the principles set forth in the Declaration of Helsinki. It will be carried out in accordance with Good Clinical Practice (GCP) as required by the "Verordnung über die Anwendung der Guten Kl inischen Praxis bei der Durchführung von klinischen Prüfungen mit Arzneimitteln zur Anwendung am Menschen (GCPVerordnung) vom 9. August 2004", based upon the guidance 2001/20/EG of the European Parliament and the ICH Guideline for Good Clinical Practice (CPMP/ICH/135/95) July 2002. Furthermore the trial is conducted according to the regulations described in the Arzneimittelgesetz AMG (e.g. $\$ 13-20$ production, $₫ 40$ to 42 Clinical trials). The Experimentelle Immuntherapie, Hautklinik, Universitätsklinikum Erlangen which will be producing the dendritic cell vaccine has legal approval for GMP production of tumor-peptide-loaded as well as RNA-transfected autologous dendritic cells (Manufacturing

\section{REFERENCES}

1. Baily C, O'Neill V, Dunne M, Cunningham M, Gullo G, Kennedy S, et al. Uveal Melanoma in Ireland. Ocul Oncol Pathol (2019) 5(3):195-204. doi: 10.1159/000492391

2. Virgili G, Gatta G, Ciccolallo L, Capocaccia R, Biggeri A, Crocetti E, et al. Incidence of Uveal Melanoma in Europe. Ophthalmology (2007) 114 (12):2309-15. doi: 10.1016/j.ophtha.2007.01.032

3. Singh AD, Turell ME, Topham AK. Uveal Melanoma: Trends in Incidence, Treatment, and Survival. Ophthalmology (2011) 118(9):1881-5. doi: 10.1016/ j.ophtha.2011.01.040

4. Sayan M, Mamidanna S, Oncel D, Jan I, Vergalasova I, Weiner J, et al. Clinical Management of Uveal Melanoma: A Comprehensive Review With a Treatment Algorithm. Radiat Oncol J (2020) 38(3):162-9. doi: 10.3857/ roj. 2020.00318

5. Fili M, Trocme E, Bergman L, See TRO, André H, Bartuma K, et al. Ruthenium-106 Versus Iodine-125 Plaque Brachytherapy of 571 Choroidal Melanomas With a Thickness of $>/=5.5 \mathrm{Mm}$. Br J Ophthalmol (2020) 104 (1):26-32. doi: 10.1136/bjophthalmol-2018-313419

6. Collaborative Ocular Melanoma Study G. Assessment of Metastatic Disease Status at Death in 435 Patients With Large Choroidal Melanoma in the Collaborative Ocular Melanoma Study (COMS): COMS Report No. 15. Arch Ophthalmol (2001) 119(5):670-6. doi: 10.1001/archopht.119.5.670

7. Kujala E, Makitie T, Kivela T. Very Long-Term Prognosis of Patients With Malignant Uveal Melanoma. Invest Ophthalmol Vis Sci (2003) 44(11):4651-9. doi: 10.1167/iovs.03-0538

8. Franklin C, Livingstone E, Roesch A, Schilling B, Schadendorf D. Immunotherapy in Melanoma: Recent Advances and Future Directions. Eur J Surg Oncol (2017) 43(3):604-11. doi: 10.1016/j.ejso.2016.07.145
License issued by the Regierung von Oberbayern on the 16th July 2009 according to AMG $\$ 13$ Absatz 1; certificate DE_BY 04_MIA_2009_0146/53.2 - ZAB - 2671.1 H 207). The trial is approved by the Paul Ehrlich Institute (PEI).

\section{AUTHOR CONTRIBUTIONS}

EK, JD, and BS-T wrote the draft of the manuscript. EK designed the figures. All authors are involved in the design, planning, or performance of the clinical trial. All authors have read and approved the final manuscript.

\section{FUNDING}

This research was funded by Hasumi International Research Foundation, 2200 Pennsylvania Avenue, NW, 4th Floor East, Washington, DC 20037, USA. Tel: + 1202 973-6459. E-Mail: office@hasumi-foundation.org.

\section{ACKNOWLEDGMENTS}

We thank our team of technicians: Michaela May, Johannes März, Martina Mathews, Marita Rosenberg, Diane Stoica, and Manuel Wiesinger and our study nurses Caroline Reck and Marlen Strobel. We thank Reinhard E. Voll for providing the constitutively active IKK $\beta$ mutant and Kris Thielemans for sharing the DC-Lamp-based MHC class II targeting technology.

9. Khoja L, Atenafu EG, Suciu S, Leyvraz S, Sato T, Marshall E, et al. MetaAnalysis in Metastatic Uveal Melanoma to Determine Progression Free and Overall Survival Benchmarks: An International Rare Cancers Initiative (IRCI) Ocular Melanoma Study. Ann Oncol (2019) 30(8):1370-80. doi: 10.1093/ annonc/mdz176

10. Pelster MS, Gruschkus SK, Bassett R, Gombos DS, Shephard M, Posada L, et al. Nivolumab and Ipilimumab in Metastatic Uveal Melanoma: Results From a Single-Arm Phase II Study. J Clin Oncol (2020) 39(6):599-607. doi: 10.1200/JCO.20.00605

11. Piulats JM, Espinosa E, de la Cruz Merino L, Varela M, Carrión LA, MartínAlgarra S, et al. Nivolumab Plus Ipilimumab for Treatment-Naive Metastatic Uveal Melanoma: An Open-Label, Multicenter, Phase II Trial by the Spanish Multidisciplinary Melanoma Group (GEM-1402). J Clin Oncol (2021) 119 (5):670-6. doi: 10.1200/JCO.20.00550

12. Heppt MV, Amaral T, Kahler KC, Heinzerling L, Hassel JC, Meissner M, et al. Combined Immune Checkpoint Blockade for Metastatic Uveal Melanoma: A Retrospective, Multi-Center Study. J Immunother Cancer (2019) 7(1):299. doi: 10.1186/s40425-019-0800-0

13. Heppt MV, Heinzerling L, Kahler KC, Forschner A, Kirchberger MC, Loquai C, et al. Prognostic Factors and Outcomes in Metastatic Uveal Melanoma Treated With Programmed Cell Death-1 or Combined PD-1/Cytotoxic TLymphocyte Antigen-4 Inhibition. Eur J Cancer (2017) 82:56-65. doi: 10.1016/j.ejca.2017.05.038

14. Najjar YG, Navrazhina K, Ding F, Bhatia R, Tsai K, Abbate K, et al. Ipilimumab Plus Nivolumab for Patients With Metastatic Uveal Melanoma: A Multicenter, Retrospective Study. J Immunother Cancer (2020) 8(1): e000331. doi: 10.1136/jitc-2019-000331

15. Koch EAT, Petzold A, Wessely A, Dippel E, Gesierich A, Gutzmer R, et al. Immune Checkpoint Blockade for Metastatic Uveal Melanoma: Patterns of 
Response and Survival According to the Presence of Hepatic and Extrahepatic Metastasis. Cancers (2021) 13(13):3359. doi: 10.3390/cancers13133359

16. Hassel JC, Heinzerling L, Aberle J, Bähr O, Eigentler TK, Grimm MO, et al. Combined Immune Checkpoint Blockade (Anti-PD-1/Anti-CTLA-4): Evaluation and Management of Adverse Drug Reactions. Cancer Treat Rev (2017) 57:36-49. doi: 10.1016/j.ctrv.2017.05.003

17. Heinzerling L, Ascierto PA, Dummer R, Gogas H, Grob JJ, Lebbe C, et al. Adverse Events 2.0-Let Us Get SERIOs: New Reporting for Adverse Event Outcomes Needed in the Era of Immunooncology. Eur J Cancer (2019) 112:29-31. doi: 10.1016/j.ejca.2019.01.015

18. Koch EAT, Nickel FT, Heinzerling L, Schulz YK, Berking C, Erdmann M. Immune Checkpoint Inhibitor-Induced Bilateral Vestibulopathy. J Immunother (2021) 44(3):114-7. doi: 10.1097/CJI.0000000000000353

19. Sato T, Nathan PD, Hernandez-Aya L, Sacco JJ, Orloff MM, Visich J, et al. Redirected T Cell Lysis in Patients With Metastatic Uveal Melanoma With Gp100-Directed TCR IMCgp100: Overall Survival Findings. J Clin Oncol (2018) 36(15_suppl):9521-1. doi: 10.1200/JCO.2018.36.15_suppl.9521

20. Piperno-Neumann S, Hassel JC, Rutkowski P, Baurain JF, Butler MO, Schlaak M, et al. Abstract CT002: Phase 3 Randomized Trial Comparing Tebentafusp With Investigator's Choice in First Line Metastatic Uveal Melanoma. Cancer Res (2021) 81(13 Supplement):CT002-2. doi: 10.1158/1538-7445.AM2021CT002

21. Moreira A, Gross S, Uslu U, Dörrie J, Kummer M, Schliep S, et al. Abstract E21024: Dendritic Cell Vaccination in Metastatic Uveal Melanoma as Compassionate Treatment: Immunological and Clinical Responses. J Clin Oncol (2019) 37 (15_suppl):e21024. doi: 10.1200/JCO.2019.37.15.15_suppl.e21024

22. Schuler-Thurner B, Bartz-Schmidt KU, Bornfeld N, Cursiefen C, Fuisting B, Grisanti S, et al. Immunotherapy of Uveal Melanoma: Vaccination Against Cancer. Multicenter Adjuvant Phase 3 Vaccination Study Using Dendritic Cells Laden With Tumor RNA for Large Newly Diagnosed Uveal Melanoma. Ophthalmologe (2015) 112(12):1017-21. doi: 10.1007/s00347-015-0162-z

23. Pfeiffer IA, Hoyer S, Gerer KF, Voll RE, Knippertz I, Gückel E, et al. Triggering of NF-kappaB in Cytokine-Matured Human DCs Generates Superior DCs for T-Cell Priming in Cancer Immunotherapy. Eur J Immunol (2014) 44 (11):3413-28. doi: 10.1002/eji.201344417

24. Bosch NC, Voll RE, Voskens CJ, Gross S, Seliger B, Schuler G, et al. NFkappaB Activation Triggers NK-Cell Stimulation by Monocyte-Derived Dendritic Cells. Ther Adv Med Oncol (2019) 11:1758835919891622. doi: $10.1177 / 1758835919891622$

25. Bonehill A, Heirman C, Tuyaerts S, Michiels A, Breckpot K, Brasseur F, et al. Messenger RNA-Electroporated Dendritic Cells Presenting MAGE-A3 Simultaneously in HLA Class I and Class II Molecules. J Immunol (2004) 172(11):6649-57. doi: 10.4049/jimmunol.172.11.6649

26. Erdmann M, Dorrie J, Schaft N, Strasser E, Hendelmeier M, Kämpgen E, et al. Effective Clinical-Scale Production of Dendritic Cell Vaccines by Monocyte Elutriation Directly in Medium, Subsequent Culture in Bags and Final Antigen Loading Using Peptides or RNA Transfection. I Immunother (2007) 30(6):663-74. doi: 10.1097/CJI.0b013e3180ca7cd6

27. Gerer KF, Hoyer S, Dorrie J, Schaft N. Electroporation of mRNA as Universal Technology Platform to Transfect a Variety of Primary Cells With Antigens and Functional Proteins. Methods Mol Biol (2017) 1499:165-78. doi: 10.1007/ 978-1-4939-6481-9_10

28. Dorrie J, Schaft N, Muller I, Wellner V, Schunder T, Hänig J, et al. Introduction of Functional Chimeric E/L-Selectin by RNA Electroporation to Target Dendritic Cells From Blood to Lymph Nodes. Cancer Immunol Immunother (2008) 57(4):467-77. doi: 10.1007/s00262-007-0385-1

29. Gross S, Erdmann M, Haendle I, Voland S, Berger T, Schultz E, et al. Twelve-Year Survival and Immune Correlates in Dendritic Cell-Vaccinated Melanoma Patients. JCI Insight (2017) 2(8):e91438. doi: 10.1172/jci.insight.91438

30. Dörrie J, Schaft N, Gross S, Ostalecki C, Eberhardt M, Vera-Gonzáles J, et al. Step by Step Optimization of mRNA-Electroporated Dendritic Cells During a Phase I/II Vaccine Trial in Stage IV Cutaneous Melanoma Patients: An Increase in Survival Correlates With Higher Immunoscore in Metastases, and Upregulation of PEBP1 in Peripheral Blood. J Dtsch Dermatol Ges (2020) 18 (S2):8-9. doi: 10.1111/ddg.14192

31. De Keersmaecker B, Claerhout S, Carrasco J, Bar I, Coerthals J, Wilgenhof S, et al. TriMix and Tumor Antigen mRNA Electroporated Dendritic Cell Vaccination Plus Ipilimumab: Link Between T-Cell Activation and Clinical
Responses in Advanced Melanoma. J Immunother Cancer (2020) 8(1): e000329. doi: 10.1136/jitc-2019-000329

32. Dörrie J, Schaft N, Schuler G, Schuler-Thurner B. Therapeutic Cancer Vaccination With Ex Vivo RNA-Transfected Dendritic Cells-An Update. Pharmaceutics (2020) 12(2):92. doi: 10.3390/pharmaceutics 12020092

33. Chen PW, Mellon JK, Mayhew E, Wang S, He YG, Hogan N, et al. Uveal Melanoma Expression of Indoleamine 2,3-Deoxygenase: Establishment of an Immune Privileged Environment by Tryptophan Depletion. Exp Eye Res (2007) 85(5):617-25. doi: 10.1016/j.exer.2007.07.014

34. Ryu YH, Kim JC. Expression of Indoleamine 2,3-Dioxygenase in Human Corneal Cells as a Local Immunosuppressive Factor. Invest Ophthalmol Vis Sci (2007) 48(9):4148-52. doi: 10.1167/iovs.05-1336

35. Bjoern J, Iversen TZ, Nitschke NJ, Andersen MH, Svane IM. Safety, Immune and Clinical Responses in Metastatic Melanoma Patients Vaccinated With a Long Peptide Derived From Indoleamine 2,3-Dioxygenase in Combination With Ipilimumab. Cytotherapy (2016) 18(8):1043-55. doi: 10.1016/j.jcyt.2016.05.010

36. Nathan P, Hassel JC, Rutkowski P, Baurain JF, Butler MO, Schlaak M, et al. Overall Survival Benefit With Tebentafusp in Metastatic Uveal Melanoma. N Engl J Med (2021) 385(13):1196-206. doi: 10.1056/NEJMoa2103485

37. Atkins MB, Robertson MJ, Gordon M, Lotze MT, DeCoste M, DuBois JS, et al. Phase I Evaluation of Intravenous Recombinant Human Interleukin 12 in Patients With Advanced Malignancies. Clin Cancer Res (1997) 3(3):409-17.

38. Portielje JE, Gratama JW, van Ojik HH, Stoter G, Kruit WH. IL-12: A Promising Adjuvant for Cancer Vaccination. Cancer Immunol Immunother (2003) 52(3):133-44. doi: 10.1007/s00262-002-0356-5

39. Gerer KF, Erdmann M, Hadrup SR, Lyngaa R, Martin LM, Voll RE, et al. Preclinical Evaluation of NF-kappaB-Triggered Dendritic Cells Expressing the Viral Oncogenic Driver of Merkel Cell Carcinoma for Therapeutic Vaccination. Ther Adv Med Oncol (2017) 9(7):451-64. doi: 10.1177/1758834017712630

40. Prommersberger S, Hofflin S, Schuler-Thurner B, Schuler G, Schaft N, Dorrie J. A New Method to Monitor Antigen-Specific CD8+ T Cells, Avoiding Additional Target Cells and the Restriction to Human Leukocyte Antigen Haplotype. Gene Ther (2015) 22(6):516-20. doi: 10.1038/gt.2015.15

41. Nielsen M, Lundegaard C, Blicher T, Lambert K, Harndahl M, Justesen S, et al. NetMHCpan, a Method for Quantitative Predictions of Peptide Binding to Any HLA-A and -B Locus Protein of Known Sequence. PLoS One (2007) 2(8): e796. doi: 10.1371/journal.pone.0000796

42. Andersen RS, Kvistborg P, Frosig TM, Pedersen NW, Lyngaa R, Bakker AH, et al. Parallel Detection of Antigen-Specific T Cell Responses by Combinatorial Encoding of MHC Multimers. Nat Protoc (2012) 7(5):891902. doi: 10.1038/nprot.2012.037

43. Danilova L, Anagnostou V, Caushi JX, Sidhom JW, Guo H, Chan HY, et al. The Mutation-Associated Neoantigen Functional Expansion of Specific T Cells (MANAFEST) Assay: A Sensitive Platform for Monitoring Antitumor Immunity. Cancer Immunol Res (2018) 6(8):888-99. doi: 10.1158/2326-6066.CIR-18-0129

Conflict of Interest: The authors declare the following potential conflict of interest: GS, NS, and JD are named as inventors on a patent on caIKK-RNAelectroporated DCs (WO/2012/055551), which is held by the FriedrichAlexander-Universtät Erlangen-Nürnberg.

The remaining authors declare that the research was conducted in the absence of any commercial or financial relationships that could be construed as a potential conflict of interest.

Publisher's Note: All claims expressed in this article are solely those of the authors and do not necessarily represent those of their affiliated organizations, or those of the publisher, the editors and the reviewers. Any product that may be evaluated in this article, or claim that may be made by its manufacturer, is not guaranteed or endorsed by the publisher.

Copyright (c) 2022 Koch, Schaft, Kummer, Berking, Schuler, Hasumi, Dörrie and Schuler-Thurner. This is an open-access article distributed under the terms of the Creative Commons Attribution License (CC BY). The use, distribution or reproduction in other forums is permitted, provided the original author(s) and the copyright owner(s) are credited and that the original publication in this journal is cited, in accordance with accepted academic practice. No use, distribution or reproduction is permitted which does not comply with these terms. 